\title{
Sociological Survey on Humanised Communication Design of Public Hospital: A Case Study
}

\author{
Zhiyong Wang, Liyao Yang, Sirui Luo \\ School of Fine Arts, Sichuan University of Science \& Engineering, Zigong, China \\ Email: matinee2005@aliyun.com
}

Received 1 June 2016; accepted 8 July 2016; published 11 July 2016

Copyright (C) 2016 by authors and Scientific Research Publishing Inc.

This work is licensed under the Creative Commons Attribution International License (CC BY). http://creativecommons.org/licenses/by/4.0/

(c) (i) Open Access

\begin{abstract}
As humanised design served for the idea of "social responsibility", this research takes a sociological survey on humanised design of in-patient departments of public hospital, as a case study, in order to present an example to value the significance of sociological survey upon reliable design. With well planned research target and communications, we take the survey methods as direct observation, questionnaire and group interview to obtain necessary information about needs of concerned people. Then, a series of design problems was found and the corresponding suggestions were made for improving solutions based upon comparative analysis. Finally, it reveals the strong relationship between social survey and improvement of humanised communication design with social responsibility.
\end{abstract}

\section{Keywords}

Sociological Survey, Humanised Communication Design, Public Hospital, Case Study

\section{Introduction}

Today, with the fast development of modern design, the idea of "humanising" draws an increasing attention and humanised design has become to play a key role in satisfaction of diversified social needs. In brief, the concept of "humanised design" means that, in the process of designing, designers should not only care about the performance of function, but they should also consider the comprehensive characteristics of user related physiology, psychology, behaviors and cultural values. Its essence is concluded in several following turnings: 1) Design position: from "technological centered" to "human centered"; 2) Design target: from "functional performance" to "satisfaction of human needs"; 3) Design idea: from "technological rationalisation" to "expression of diversified 
culture"; 4) Design procedure: from "mechanical engineering" to "sociology and humanities"; 5) Design value: from "the objective" to "the subjective".

Since the public have strong demands for qualified services provided by modern public service system, "humanised design" could be a good assistant for services offering in public system. This research takes the in-patient departments of public hospital of Zigong (a medium sized city in southwest China) as a case study, and has the objectives to present how the sociological survey could help designer make a reliable and social responsible design within visual communication system of public service. As a practical example, it suggests the applied values for those designers who take the similar interest in public service and social responsibilities.

\section{Theory and Method}

Victor Papanek has stated that modern design should undertake the social responsibility seriously. He named it as "design ethics": Modern design is not only regarded as a way of functional fulfillment for a specific problem, but also as an approach to serve for public welfare and social management (Papanek, 2013).

Under the theoretical background of social responsible design (Wang, 2002; Pevsner, 2004; Tatum, 2004; Bonsiepe, 2006; Danko, 2008; Pan, 2012; Manzini, 2014; Tong, 2014; Corby, 2016), this research followed the procedure and method (Giddens, 2003; Burke, 2010) which are in attempt to achieve the target aiming to discover the "humanised design" related problems and give the revising suggestions based upon the reasonable survey and comparative analysis. Research procedure: 1) Research target setting, 2) Seminar, 3) Sociological survey, 4) Analysis based on survey data, 5) Results presenting. And with the following survey methods: 1) Literature reviewing: to study on the existed literature to find some hints of potential problems within this research, 2) Observing: to find problems by direct observation, 3) Questionnaire: to obtain opinions from patients and their family members, 4) Group interviewing: to obtain opinions from doctors and nurses.

For the sample of this research, we chose (in random sampling) 20 patients and their family members as the respondents of questionnaire, which include 13 patients and 7 family members. Then, we invited 5 doctors and nurses working in public hospital as the interviewees of group interviewing, which include 2 doctors and 3 nurses. Nevertheless, the people whose behaviour is one of the targets in direct observation are totally unconditioned.

\section{Survey and Results}

We defined the range of surveying in advance, so as to certain the research objects. The communication design system in Hepatology and Neurosurgery of in-patient department of The Third People's Hospital of Zigong were both chosen as our survey objects, since they share the same floor and some facilities of the building. Besides, the difficulty of survey could be well controlled because of the defined small range of survey in only two departments. Firstly, we visited the management department of the hospital and received the official permission of the survey planning, along with the effective communication with the related staffs in the concerned departments. Then, with the reference found in literature study keeping in mind, we began to take the direct observation for the environment and people behaviours in the concerned departments. The direct observation was taken twice within two weeks. We made a seminar shortly after the observation, based upon the photos and narrations. As a result, the preparatory problems related with humanised communication design were found and have been generalised below: 1) Passageway is congested in some extend because of additional beds and facilities, with potential dangers, 2) The floor shared by concerned departments has three lifts and stairways, the middle one is overloaded sometimes but the rest two (the left and the right) usually are laid aside, 3) The patients and their family members responsible for attending aired clothes freely because of no planned area for this kind of service, 4) Some people get use to have a rest and even smoke in stairway, with potential dangers, 5) There is no reasonable way to insulate the restroom and drinking-water supplying, as they shared the same area, 6) There is no efficient visual guide to remind exit way in stairway, 7) There is no efficient visual guide to remind slipping in passageway, 8) There is no efficient visual guide to remind correct use of fire hydrant, fire extinguisher, and fire alarm.

With these problems as survey basis, we took the questionnaire (Appendix 1) three times in three weeks (the two departments receive in average 40 patients per week), in which 20 patients and their family members were selected as respondents (13 patients and 7 family members), so as to clarify how the mentioned design problems they would weight and if any other problem they would like to pay attention to. As a result (Table 1), the refined problems related with humanised communication design were confirmed below. 
Table 1. A Percentage statistics of questionnaire result.

\begin{tabular}{cc}
\hline Problems & Percentage of respondents' agreement \\
\hline Smoking in stairway & $100 \%$ \\
Clothes airing & $92 \%$ \\
Emergency exit & $70 \%$ \\
Correct use of fire hydrant, etc. & $45 \%$ \\
\hline
\end{tabular}

Problem one: some people get use to have a rest and even smoke in stairway, which could lead to some potential dangers (Figure 1). Almost 100\% of respondents disagree with this behaviour. First of all, it could become a fatal block while emergency evacuating. Further, although having no smoking marking on the wall, some people still were smoking there. It is a harmful behaviour for the health of patients and others.

Problem two: the patients and their family members aired clothes freely because of no planned area for this kind of service (Figure 2). Many patients and the family members complained that they cannot find a suitable place to air the clothes, let alone the efficient visual guide for this specific area. According to the questionnaire, nearly $92 \%$ of respondents considered it a serious problem, especially those who lived far away from hospital and were no convenience of frequent clothes cleaning at home.

Problem three: There is no efficient visual guide to remind exit way in stairway, which could lead to some potential dangers (Figure 3). Around $70 \%$ of respondents insist to choose the middle stairway, which implies the users have little idea about escaping route, again, the invalid of visual guiding on emergency evacuating.

Problem four: There is no efficient visual guide to remind correct use of fire hydrant, fire extinguisher, and fire alarm (Figure 4). At least $45 \%$ of respondents say that they can hardly know how to use the fire hydrant, fire extinguisher, and fire alarm correctly. It revealed the deficiency of instruction and could result in fatal ends when fire accident happened.

After summarised the problems obtained from questionnaire, we organised a group interview. Two doctors and three nurses from the concerned two departments were invited to attend the interview. This group interview lasted 45 minutes. From the interview, we learned that all interviewees thought the instruction of behaviour for patients is a serious matter, but the means of instruction is quite under the effective level. We summarised this interview result as another problem:

Problem five: the behavioural instruction for patients (and their family members responsible for attending) is ever a very important but burdensome work. The doctors and nurses did not have a way to cope with this matter efficiently yet. They wish they could receive help in terms of communication design.

\section{Suggestions of Communication Design Solution}

According to the summarised problems from observation, questionnaire, and interview, we endeavoured to give the suggestions of communication design solution. The suggestions for design improvement are presented responding to each refined problem above.

Suggestion for problem one: in order to educate people stop smoking and unnecessary resting in stairway, we suggest that a visual design should be made as the sign for those people who are inclining to have a rest and smoking there. The key point of this design is, it should be designed and placed effectively based upon the full understanding on the behavioural and psychological characteristics, and the people could be well informed just before the rejected behaviours happened. For example, to visually "reduce their comfort there or evoke their self-accusation" could be the considerable alternatives.

Suggestion for problem two: if the patients and their family members did have the strong need for airing clothes in hospital, it is necessary to regulate this behaviour by means of well planned clothes airing area. We suggest that the area should be planned with reasonable visual guide and marks for regulating, along with product design served for this specific need, such as drying rack, etc. another option is to offer self-service dryer with regulated visual instruction. But this kind of alternatives will give rise to obvious economic cost rising and the potential users may refuse it.

Suggestion for problem three: in order to instruct people to choose an appropriate escaping route under any emergency situation, we suggest that a systematic visual guide should be designed and set in every possible place where people start to escape. Especially, we strongly present the advice which asks for visual guides not 


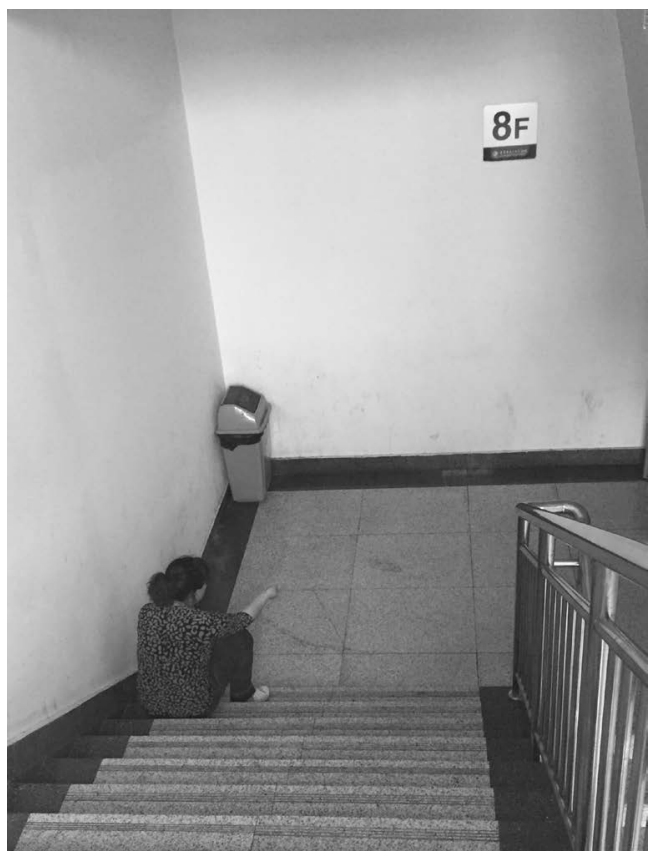

Figure 1. Example of problem one.

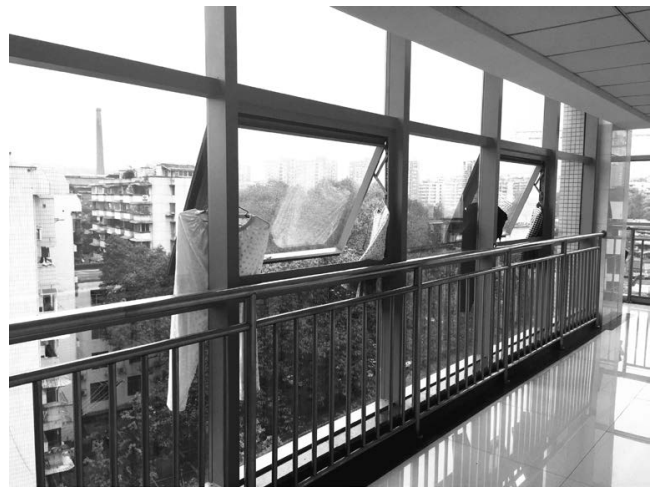

Figure 2. Example of problem two.

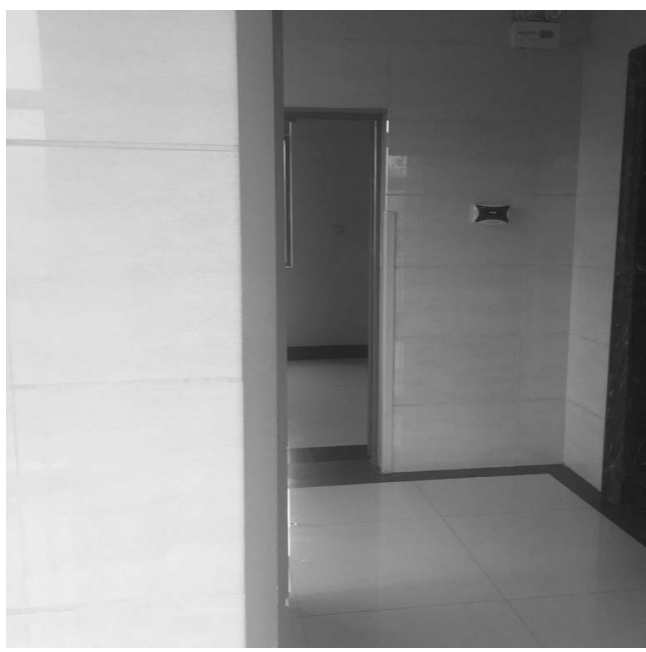

Figure 3. Example of problem three. 
only on the wall, but also on the floor within a systematic consideration, with design of floor painting or product design of guiding set under floor.

Suggestion for problem four: in order to inform people to use fire hydrant, fire extinguisher, and fire alarm correctly, we suggest that a visual instruction with full illustration and graphics is necessary for offering impactful information for the potential users. Hospital could invite those designers with experienced illustration skills to make the visual instruction for this particular usage, which could change the dull information of instruction to an interesting one.

Suggestion for problem five: a new method of behaviour instruction for patients and their family members could be made to reduce the hardship and burden of hospital staffs. We suggest that some new media design could assist doctors and nurses' work accompanied by printed materials, such as brochure design. Both educational video programme on LED display screen (in the hall or in the wards) and APP of mobile phone could play an important role on it, as it is becoming a social fact that more and more people were the smart-phone users and they increasingly got use to play APP of mobile phone (Table 2).

Limitations: this kind of sociological survey should be carried out for a specific design task or assignment. It is hardly to be the general regulation or guide for humanised communication design of public service, such as in public hospital. Every design task for public service should take full consideration of diversified conditions in advance.

\section{Conclusion}

Modern design is not only a work of arbitrary artistic expression. It should follow the method and procedure which aim to achieve a target set in advance. If any design will undertake the social responsibility, the designer should keep this idea deep in mind. The survey method from sociology could help designer find a reasonable reference to make creativities in design, in which the specific ways, such as observation, questionnaire, and in terviewing, do play a role. It means that we could fully understand the needs of people whom we manage to

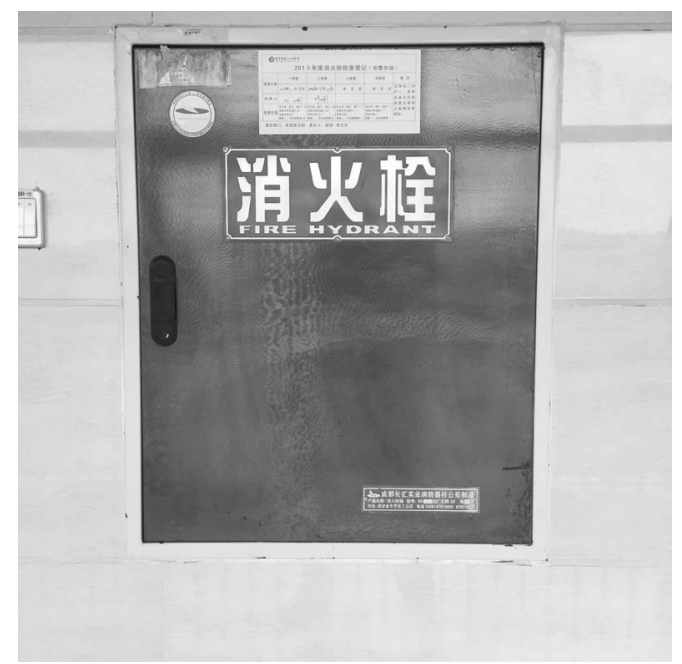

Figure 4. Example of problem four.

Table 2. Suggestions responding to problems.

\begin{tabular}{cc}
\hline Problems & Suggestions \\
\hline $\begin{array}{c}\text { Rest and smoking in stairway } \\
\text { Clothes airing }\end{array}$ & $\begin{array}{c}\text { Effective visual signs } \\
\text { Emergency exit }\end{array}$ \\
$\begin{array}{c}\text { Planned visual area with product design } \\
\text { Self-service dryer with visual instruction } \\
\text { Systematic visual guide }\end{array}$ \\
Burdensome work of instruction & $\begin{array}{c}\text { Visual instruction with interesting illustration } \\
\text { New media design (LED display, Apps, etc.) } \\
\text { Printed design (brochure, etc.) }\end{array}$ \\
\hline
\end{tabular}


serve for. Consequently, based upon well performed sociological survey and its results, the design solutions are more likely to be reliable.

\section{References}

Bonsiepe, G. (2006). Design and Democracy. Design Issue, 22, 27-34. http://dx.doi.org/10.1162/desi.2006.22.2.27

Burke, P. (2010). History and Social Theory. Shanghai: Shanghai People's Publishing House.

Corby, T., Williams, D., Sheth, V., \& Dhar, V. (2016). I Stood Up: Social Design in Practice. Art and Design Review, 4, 3036. http://dx.doi.org/10.4236/adr.2016.42005

Danko, S. (2008). Humanizing Design through Narrative Inquiry. Journal of Interior Design, 31, 10-28. http://dx.doi.org/10.1111/j.1939-1668.2005.tb00408.x

Giddens, A. (2003). Sociology. Beijing: Peking University Press.

Pan, J. W. (2012). The Research of Humanized Design of Mechanical Equipment. Applied Mechanics and Materials, 1968, 890-893. http://dx.doi.org/10.1162/DESI_a_00248

Manzini, E. (2014). Making Things Happen: Social Innovation and Design. Design Issue, 30, 57-66.

Papanek, V. (2013). Design for the Real World. Beijing: China CITIC Press.

Pevsner, N. (2004). Pioneers of Modern Design: from William Morris to Walter Gropius. Beijing: China Architecture \& Building Press. http://dx.doi.org/10.1162/0747936041423307

Tatum, J. S. (2004). The Challenge of Responsible Design. Design Issue, 20, 66-80.

Wang, S. Z. (2002). A History of Modern Design. Beijing: China Youth Press.

Tong, Y. Q. (2014). Extraction of Humanized Design in Industrial Design Application. Applied Mechanics and Materials, $3589,275-278$. 


\section{Appendix 1}

\section{Basic information of respondent}

Name:

Age:

Identity: patient / family member of patient

Telephone:

\section{Questions}

1. Is the Passageway crowed?

A yes $\mathrm{B}$ no $\mathrm{C}$ indifferent

2. Which one will you choose if you want to use lift or stairway (according to service desk)?

A the left $\mathrm{B}$ the middle $\mathrm{C}$ the right

3. Is it convenient if you want to air clothes in hospital?

A yes $\mathrm{B}$ no $\mathrm{C}$ indifferent

4. Do you feel it is a trouble if anyone has a rest or smoking in stairway?

A yes $\mathrm{B}$ no $\mathrm{C}$ indifferent

5. Is it convenient that the restroom and drinking-water supplying system shared same area? $\mathrm{A}$ yes $\mathrm{B}$ no $\mathrm{C}$ indifferent

6. Is visual guide efficient to remind exit way in stairway?

A yes $\mathrm{B}$ no $\mathrm{C}$ indifferent

7. Is visual guide efficient to remind slipping in passageway?

A yes $\mathrm{B}$ no $\mathrm{C}$ indifferent

8. Is visual guide efficient to remind correct use of fire hydrant, extinguisher, and alarm?

A yes $\mathrm{B}$ no $\mathrm{C}$ indifferent

\section{Other advice or suggestion}




\section{Submit or recommend next manuscript to SCIRP and we will provide best service for you:}

Accepting pre-submission inquiries through Email, Facebook, LinkedIn, Twitter, etc.

A wide selection of journals (inclusive of 9 subjects, more than 200 journals)

Providing 24-hour high-quality service

User-friendly online submission system

Fair and swift peer-review system

Efficient typesetting and proofreading procedure

Display of the result of downloads and visits, as well as the number of cited articles

Maximum dissemination of your research work

Submit your manuscript at: http://papersubmission.scirp.org/ 